\title{
Aryl Amination with Soluble Weak Base Enabled by a Water-Assisted Mechanism
}

\author{
Sii Hong Lau, ${ }^{\dagger}$ Peng Yu, ${ }^{\dagger}$ Liye Chen, ${ }^{\dagger}$ Christina B. Madsen-Duggan, ${ }^{\natural}$ Michael J. Williams, ${ }^{\natural}$ and Brad P. Carrow ${ }^{\dagger, *}$ \\ ${ }^{+}$Department of Chemistry, Princeton University, Princeton, New Jersey 08544, United States

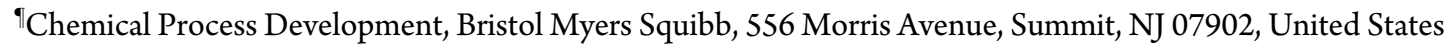

\begin{abstract}
Amination of aryl halides has become one of the most commonly practiced C-N bond-forming reactions in pharmaceutical and laboratory synthesis. The widespread use of strong or poorly soluble inorganic bases for amine activation nevertheless complicates the compatibility of this important reaction class with sensitive substrates as well as applications in flow and automated synthesis, to name a few. We report a palladium-catalyzed $\mathrm{C}-\mathrm{N}$ coupling using $\mathrm{Et}_{3} \mathrm{~N}$ as a weak, soluble base, which allows a broad substrate scope that includes bromo- and chloro(hetero)arenes, primary anilines, secondary amines, and amide type nucleophiles together with tolerance for a range of base-sensitive functional groups. Mechanistic data have established a unique pathway for these reactions in which water serves multiple beneficial roles. In particular, ionization of a neutral catalytic intermediate via halide displacement by $\mathrm{H}_{2} \mathrm{O}$ generates, after proton loss, a coordinatively-unsaturated $\mathrm{Pd}-\mathrm{OH}$ species that can bind amine substrate triggering intramolecular $\mathrm{N}-\mathrm{H}$ heterolysis. This water-assisted pathway operates efficiently with even weak terminal bases, such as $\mathrm{Et}_{3} \mathrm{~N}$. The use of a simple, commercially available ligand, $\mathrm{PAd}_{3}$, is key to this water-assisted mechanism by promoting coordinative unsaturation in catalytic intermediates responsible for the heterolytic activation of strong element-hydrogen bonds, which enables broad compatibility of carbon-heteroatom cross-coupling reactions with sensitive substrates and functionality.
\end{abstract}

\section{INTRODUCTION}

Carbon-nitrogen cross-coupling reactions using palladium and related late transition metal catalysts are some of the most widely utilized methods for the synthesis of pharmaceuticals, agrochemicals, organic electronic materials, and fine chemicals. ${ }^{1}$ Over that past two decades, numerous innovations in the ligand(s) and precatalyst structure of palladium complexes have been made that have expanded the diversity of organic electrophile and amine nucleophile classes applicable to this transformation. ${ }^{2}$ On the other hand, the bases used for Buchwald-Hartwig amination have evolved to a lesser extent; modern $\mathrm{C}-\mathrm{N}$ coupling methods still rely heavily on ionic bases, such as sodium tert-butoxide or lithium hexamethyldisilazide (LiHMDS). ${ }^{3}$ Such strong ionic bases impose compatibility issues with functional groups susceptible to nucleophilic attack, such as carboxylic acids, esters, nitriles, nitro groups, and carbonyl groups with enolizable sites, to name a few. ${ }^{4}$ Amination reactions conducted on scale in organic solvents using common inorganic bases, such as hydroxide, carbonate and phosphate salts, also frequently incur reproducibility issues. ${ }^{5}$ High-throughput experimentation (HTE) ${ }^{6}$ and continuous flow chemistry ${ }^{7}$ face similar issues where base insolubility can present either an inconvenience or major hurdle, respectively. ${ }^{8}$ The development of new methods that operate efficiently with weak, soluble, and inexpensive bases could circumvent all of these issues and broaden the applicability of $\mathrm{C}-\mathrm{N}$ coupling in industrial applications.

The difficulty of transitioning $\mathrm{C}-\mathrm{N}$ coupling toward the use of weak, soluble bases can be attributed, at least in part, to a mechanistic challenge using conventional Pd catalysts, such as those ligated by BINAP as a prototypical example. A combined computational and experimental mechanistic study by Norrby found that soluble neutral bases such as the phosphazene tert-butylimino-
Scheme 1. Base effects in Pd-catalyzed C-N coupling.

A. Conventional conditions (strong ionic bases)

Norrby, 2014:

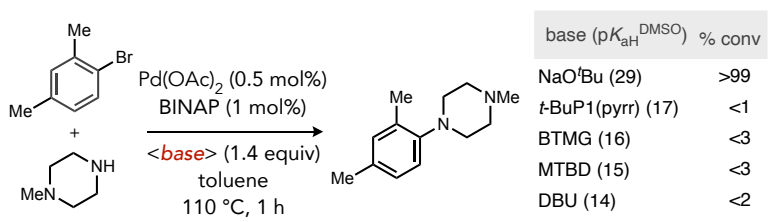

B. lonic pathway (soluble amine bases)

Buchwald, 2018:
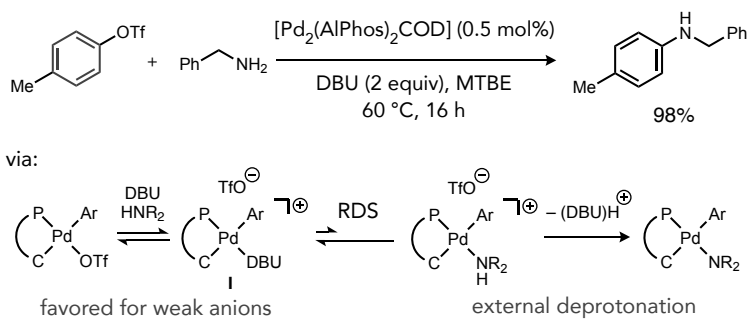

C. Ambiphilic, water-assisted pathway (this work)

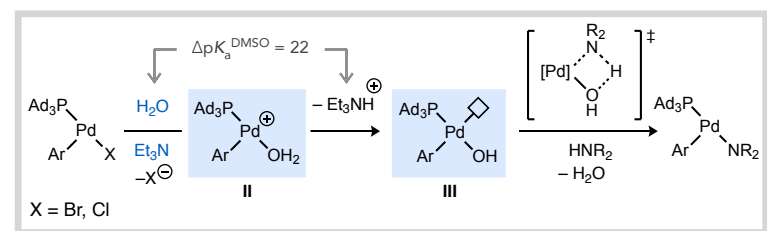

- Coordination-induced acidification (II)

- Lewis acid \& Brønsted base synergism (III)

- Base inhibition (i.e., I) mitigated by $\mathrm{H}_{2} \mathrm{O}$

- Amination of $\mathrm{ArBr}$ and $\mathrm{ArCl}$ enabled with a soluble weak base 
tri(pyrrolidino)phosphorene ( $t$-BuP1(pyrr)), Barton's guanidine base 2-tert-butyl-1,1,3,3-tetramethylguanidine (BTMG), or the amidines 7-methyl-1,5,7-triazabicyclo[4.4.0] dec-5-ene (MTBD) and 1,8-diazabicyclo[5.4.0] undec-7-ene (DBU) perform poorly relative to $\mathrm{NaO}^{t} \mathrm{Bu}$ as a prototypical strong ionic base (Scheme 1a). ${ }^{9}$ This striking difference was correlated to the preference of the system to maintain neutral reaction pathways in nonpolar organic solvents because ionization of neutral metal halide complexes is too energetically unfavorable. Ionic bases are more reactive in the neutral manifold, either by deprotonating a neutral amine-coordinated Pd intermediate or through salt metathesis to generate a basic Pd-alkoxo intermediate that can deprotonate an amine substrate. ${ }^{10}$ Furthermore, amine bases such as DBU were implicated in catalyst inhibition by competitively binding Pd to form off-cycle intermediates.

Several studies have recently demonstrated that newer generation $\mathrm{Pd}$ complexes featuring hindered phosphines can catalyze $\mathrm{C}-\mathrm{N}$ coupling reactions with soluble bases. The phosphazene superbase $\mathrm{P}_{2} \mathrm{Et}$ enabled homogeneous aminations suitable for HTE screening on micro- or nanomole scale. ${ }^{11}$ However, phosphazene bases are prohibitively expensive for large scale applications. Buchwald developed a well-defined Pd precatalyst coordinated by the hindered terphenyl phosphine AlPhos, which catalyzes amination reactions of aryl triflates or some halides with unhindered primary amines and amides using DBU as base. ${ }^{12}$ Palladium catalysts featuring other phosphine ligands, such as Xantphos, DPEphos, and Josiphos have also emerged for DBU-promoted C-N coupling. ${ }^{13,5}$ Additionally, photoredox $^{14}$ or electrochemical ${ }^{15}$ conditions have been demonstrated to provide sufficient driving force to utilize weak bases, such as DABCO.

Importantly in the (AlPhos)Pd-catalyzed reactions, a ligand-enabled mechanism change from a typical neutral to an ionic pathway for N-H cleavage was identified, which facilitates efficient turnover with a weak base (Scheme $1 \mathrm{~b}$ ). ${ }^{16}$ Dissociation of a triflate anion and coordination of amine leads to acidification of the bound substrate to such an extent that the cationic intermediate is susceptible to external N-H deprotonation by even moderate bases, like DBU. Furthermore, the turnover-limiting step of these reactions was found to be dissociation of DBU from an off-cycle intermediate coordinated by this base, which highlights another challenge facing weak base amination reactions involving Lewis basic (strongly coordinating) reagents. Extending the applicable weak base further to tertiary amines remains highly desirable in this area due to their low cost, tunable properties, and low basicity in comparison to other soluble bases such as amidines, guanidines, or phosphazenes. To this end, a Ni-catalyzed amination of aryl triflates with anilines and triethylamine as base was recently reported by Buchwald. ${ }^{17}$ An ionic catalytic pathway is also believed to operate in this system for which aryl bromides and chlorides are more challenging substrates, possibly due to stronger halide coordination to the transition metal that inhibits ionization and amine binding. An outstanding need thus remains for the identification of new catalysts that can promote weak base coupling with widely available halo(hetero)arene electrophiles, as opposed to specialty aryl triflates, with a variety of amine nucleophile classes using an "ideal" soluble weak base, such as $\mathrm{Et}_{3} \mathrm{~N}^{18}$

Our group previously reported a coordinatively-unsaturated organopalladium catalyst, $\mathrm{Pd}\left(\mathrm{PAd}_{3}\right)\left(\mathrm{Ar}^{\mathrm{F}}\right) \mathrm{Br} \mathbf{1}\left(\mathrm{Ar}^{\mathrm{F}}=4-\mathrm{FC}_{6} \mathrm{H}_{4}\right)$, which functions as an on-cycle catalyst for Suzuki-Miyaura coupling with organoboronic acids prone to fast base-catalyzed protodeboronation (PDB). ${ }^{19}$ A key aspect of this development was achieving efficient catalytic turnover using the combination of $\mathrm{H}_{2} \mathrm{O}$ and a weak, soluble amine base $\left(\mathrm{Et}_{3} \mathrm{~N}\right)$. Stoichiometric mechanistic experiments implicated ionization of $\mathrm{Pd}\left(\mathrm{PAd}_{3}\right)\left(\mathrm{Ar}^{\mathrm{F}}\right) \mathrm{X}(\mathrm{X}=\mathrm{Br}, \mathrm{Cl})$ complexes to cationic species $\left[\mathrm{Pd}\left(\mathrm{PAd}_{3}\right)\left(\mathrm{Ar}^{\mathrm{F}}\right)(\mathrm{S})\right]^{+}(\mathrm{S}=$ water, solvent $),{ }^{20}$ which undergo facile deprotonation of the acidified aqua ligand even by mild bases (Scheme 1c) ${ }^{21}$ It is thus possible to access coordinatively unsaturated Pd-hydoxo intermediates (III, Scheme 1c) that feature both Lewis acidic (open coordination site) and Lewis/Brønsted basic properties in the absence of stoichiometric ionic bases (i.e., hydroxide or alkoxides). ${ }^{22}$ Because palladium hydroxo and alkoxo complexes have been implicated in numerous other catalytic processes but are classically accessed by reactions involving stoichiometric strong bases (e.g., $\mathrm{NaOH}, \mathrm{NaO}^{t} \mathrm{Bu}$ ), it may be possible to leverage the water-assisted pathway we uncovered to promote a range of catalytic transformations under conditions milder than what was possible using traditional catalysts.

The Brønsted basicity of species such as III should also be reactive toward activation of strong element-hydrogen bonds, such as in the amine activation step ( $\mathrm{N}-\mathrm{H}$ heterolysis) of Buchwald-Hartwig amination. ${ }^{23}$ While such species can be generated from stoichiometric reactions of $\mathrm{Pd}$ (II)-halide complexes with hydroxide, ${ }^{25}$ the intermediacy of palladium hydroxo complexes in $\mathrm{N}-\mathrm{H}$ bond activation has to our knowledge not been unambiguously established in a catalytic setting. ${ }^{24}$ We hypothesized that the coordination of amine to the catalyst open site should strongly acidify the $\mathrm{N}-\mathrm{H}$ bond, and the cis-hydroxo ligand would then be poised for intramolecular deprotonation to extrude water and generate the penultimate Pdamido catalytic intermediate. Here we report a method for aryl amination of bromo- and chloro(hetero)arenes using the on-cycle catalyst $\mathbf{1}$ and $\mathrm{Et}_{3} \mathrm{~N}$ as a soluble weak base. Water is an essential component for these reactions, and mechanistic data implicate three complementary roles by which water can facilitate the overall catalytic process: i) acceleration of an inner sphere heterolysis of the substrate $\mathrm{N}-\mathrm{H}$ bond, ii) driving an unfavorable ionization of neutral palladium halide species by sequestering halide into an aqueous phase, and iii) shunting catalyst away from an inhibited, base-coordinated state.

\section{RESULTS AND DISCUSSION}

High-throughput experimentation (HTE) techniques were used to assess the multi-dimensional influence of solvent, amine base, and water on a model reaction between 4-chlorobiphenyl and 4-nitroaniline catalyzed by complex 1 ( $1 \mathrm{~mol} \%)$ to form amine $2 .{ }^{26}$ Representative results of this three-dimensional screening are visualized in the heat plot shown in Figure 1 (see Tables S1 and S2 for tabular data). The solvent dimension did not indicate a clear contrast in conversion as a function of solvent polarity. Both polar (a)protic (e.g., $t$ amyl alcohol, DMF) and relatively non-polar (e.g., toluene, DME, 2methyl tetrahydrofuran) solvents were associated with significant conversion. On the other hand, $\mathrm{Et}_{3} \mathrm{~N}\left(\mathrm{p} K_{\mathrm{aH}}{ }^{\text {DMSO }}=9\right)$ gave the best average conversion versus other tertiary amines (e.g., diisopropylethylamine, $\mathrm{N}$-methyl morpholine) in the base dimension. Counterintuitively, stronger bases $\left(\mathrm{p} K_{\mathrm{a}}^{\text {DMSO }}\right)$ such as MTBD $(15)$, DBU (14), or tetramethylguanidine (13) were generally inferior to $\mathrm{Et}_{3} \mathrm{~N}$, which contrasts the base trends typically observed in $\mathrm{C}-\mathrm{N}$ coupling, even compared to a recently-developed weak base method using AlPhos-coordinated Pd catalysts. ${ }^{16}$ Importantly, reactions conducted with more water performed better regardless of the choice of base. 

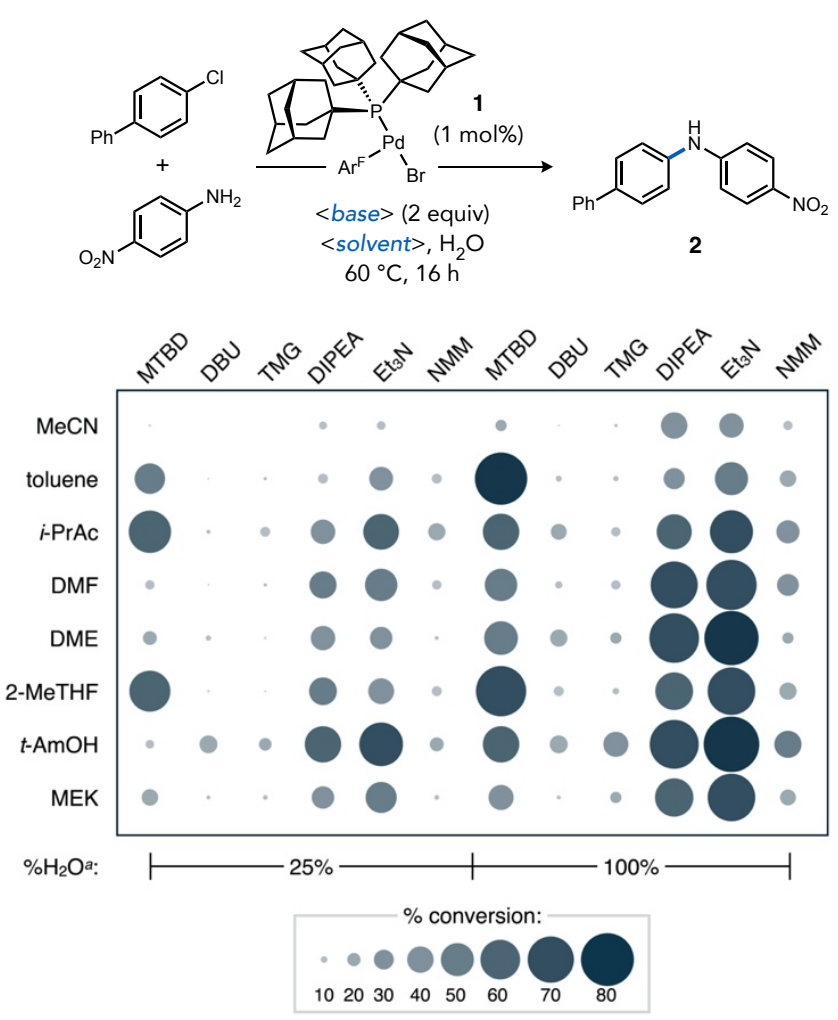

Figure 1. Heat plot for survey of soluble amine bases under BuchwaldHartwig amination conditions with water co-solvent. $\mathrm{Ar}^{\mathrm{F}}=4-\mathrm{FC}_{6} \mathrm{H}_{4}$. ${ }^{a}$ Versus total solvent volume.

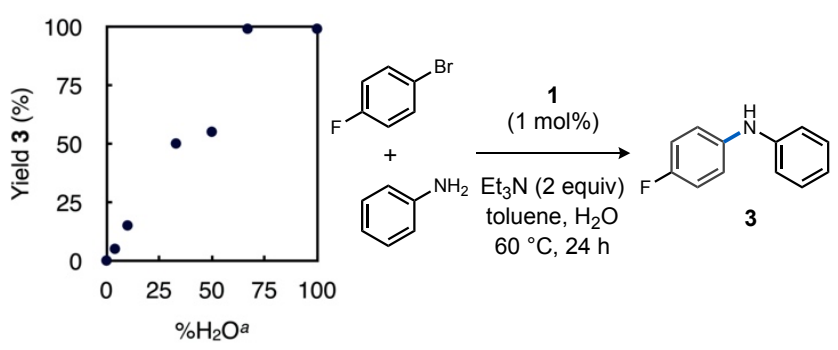

Figure 2. Optimization of water assistance during weak base BuchwaldHartwig amination. Yield determined by ${ }^{19} \mathrm{~F}$ NMR versus $\mathrm{CF}_{3} \mathrm{C}_{6} \mathrm{H}_{5}$ as internal standard. ${ }^{2}$ Versus total toluene volume.

Additional optimization confirmed water loading as a crucial dimension for achieving high reaction conversions (Figure 2), as determined by formation of $\mathbf{3}$ by ${ }^{19} \mathrm{~F}$ NMR spectroscopy during reactions of 1-bromo-4-fluorobenzene with aniline. Together with an increase in reaction temperature from 60 to $80^{\circ} \mathrm{C}$, adjusting the solvent/water ratio to at least $2: 3$ gave markedly improved yields after $6 \mathrm{~h}$. It is worth noting we believe the better performance of toluene in this model reaction versus the HTE screen may reflect a solubility artifact during catalyst dosing (compare Tables S1 and S2). In subsequent methodology studies (Tables S3-S5), a 1:4 mixture of toluene and water was ultimately selected as the most versatile mixture across different haloarene and amine combinations.

A variety of chloro- and bromo(hetero)arene electrophiles and nucleophiles were tested to explore the scope of a method featuring this $\left(\mathrm{Ad}_{3} \mathrm{P}\right) \mathrm{Pd}$-catalyzed, water-assisted reaction pathway (Table 1). For primary aryl amines, products generated from an electron-poor nucleophile (4), which are more challenging versus simple amines, ${ }^{14,27}$ and hindered aniline (5) occurred in $92 \%$ and $72 \%$ isolated yield, respectively, suggesting good tolerance to variations in aniline electronic and steric properties. Chemoselective oxidative addition favoring bromide over triflate or chloride is confirmed by formation of $6,12,13,18$, and 27 in $61-87 \%$ isolated yields. This orthogonality makes bond constructions at different $\mathrm{C}-\mathrm{X}$ bonds viable and also complements previous $\mathrm{C}-\mathrm{N}$ coupling methods favoring activation of aryl triflates. Heteroaryl chlorides, such as those containing thiophene (7) and pyrimidine (8) motifs, were compatible substrates under the reaction conditions. Reactions using heterocyclic amines such as 5-aminoindole (9) and 3-amino-2-methoxypyridine (10) underwent arylation in high yield ( $84 \%$ and $91 \%$, respectively).

Secondary anilines that underwent arylation in good to excellent yields (79-98\%) include carbazole (12), phenothiazine (13), indoline (14), and $N$-methylaniline (15). Aliphatic secondary amines are also competent nucleophiles to generate 16-18 in $61-83 \%$ isolated yields, the latter of which involved the drug amoxapine as the nucleophile. As a point of comparison, secondary amines were shown to be poor substrates in previous $\mathrm{C}-\mathrm{N}$ coupling strategies with organic base, presumably due to steric clash with the extremely hindered ligands used. ${ }^{13,17}$ The amide nucleophile 2 -azetidinone or the protected ammonia equivalent $t$-butyl carbamate generated 19 and 20 in $89 \%$ and $97 \%$ yields, respectively. Hydrazine derivatives that are useful functional handles for heterocycle synthesis, ${ }^{1 a}$ such as 1-Boc-1methylhydrazide or benzophenone hydrazone, were also suitable nucleophiles for this method generating $\mathbf{2 1}$ and $\mathbf{2 2}$ in 69\% and 80\% isolated yields, respectively. These results highlight versatility of this water-assisted method across a spectrum of nucleophile classes that sample a broad range of $\mathrm{N}-\mathrm{H} \mathrm{p} K_{\mathrm{a}}$ and size.

Drug-like electrophiles were also explored to gauge the tolerance of the catalyst and water-assisted method to more complex functionality. Reaction of 4-fluoroaniline with the Merck informer compounds $\mathrm{X} 2$, X3, X4, X6, or X8 generated amination products 23-27 in $76-98 \%$ isolated yields. ${ }^{28}$ The high yields in these reactions indicate the synthetic utility of a weak base strategy compared against established catalytic or stoichiometric $\mathrm{C}-\mathrm{N}$ coupling of these substrates using strong bases. ${ }^{11 \mathrm{~d}, 29}$

Importantly, we envisioned this weak base method should engender improved compatibility toward base-sensitive functionality. Ketone and ester functional groups with enolizable sites were well-tolerated, as exemplified by the moderate to good yields obtained for formation of products 7 (45\%), $\mathbf{1 9}$ (89\%), $\mathbf{2 5}$ (94\%), $\mathbf{2 6}$ (98\%), $\mathbf{2 8}$ (90\%), and 31 (58\%). Formation of 17 and 18 in 89\% and 61\% yield, respectively, demonstrate tolerance of nitrile and nitro groups. Functionalization of the commercial drugs indomethacin, fenofibrate, and haloperidol in 51\%, 90\%, and 58\% isolated yields, respectively, further highlight both the compatibility of this weak base amination method with chloroarenes as well as with protic functional groups (e.g., carboxylic acid in 29 and alcohol in 31). Several amination reactions were also conducted in neat water (e.g., 4, 6, and 14), which demonstrate that catalyst 1 can operate under single phase conditions that could be advantageous for green chemistry ${ }^{30,31}$ or biorthogonal ${ }^{32}$ applications and also hints that the beneficial role(s) of water may extend beyond just sequestration of halide away from the organic solvent phase where catalyst resides.

Amination of the chloroarene fenofibrate was selected to evaluate the scalability of the method. Preliminary reactions (Table S7) on half-gram scale at $98{ }^{\circ} \mathrm{C}$ indicated comparably high conversions for reactions in toluene, anisole, cyclopropyl methyl ether, or $t$-amyl 


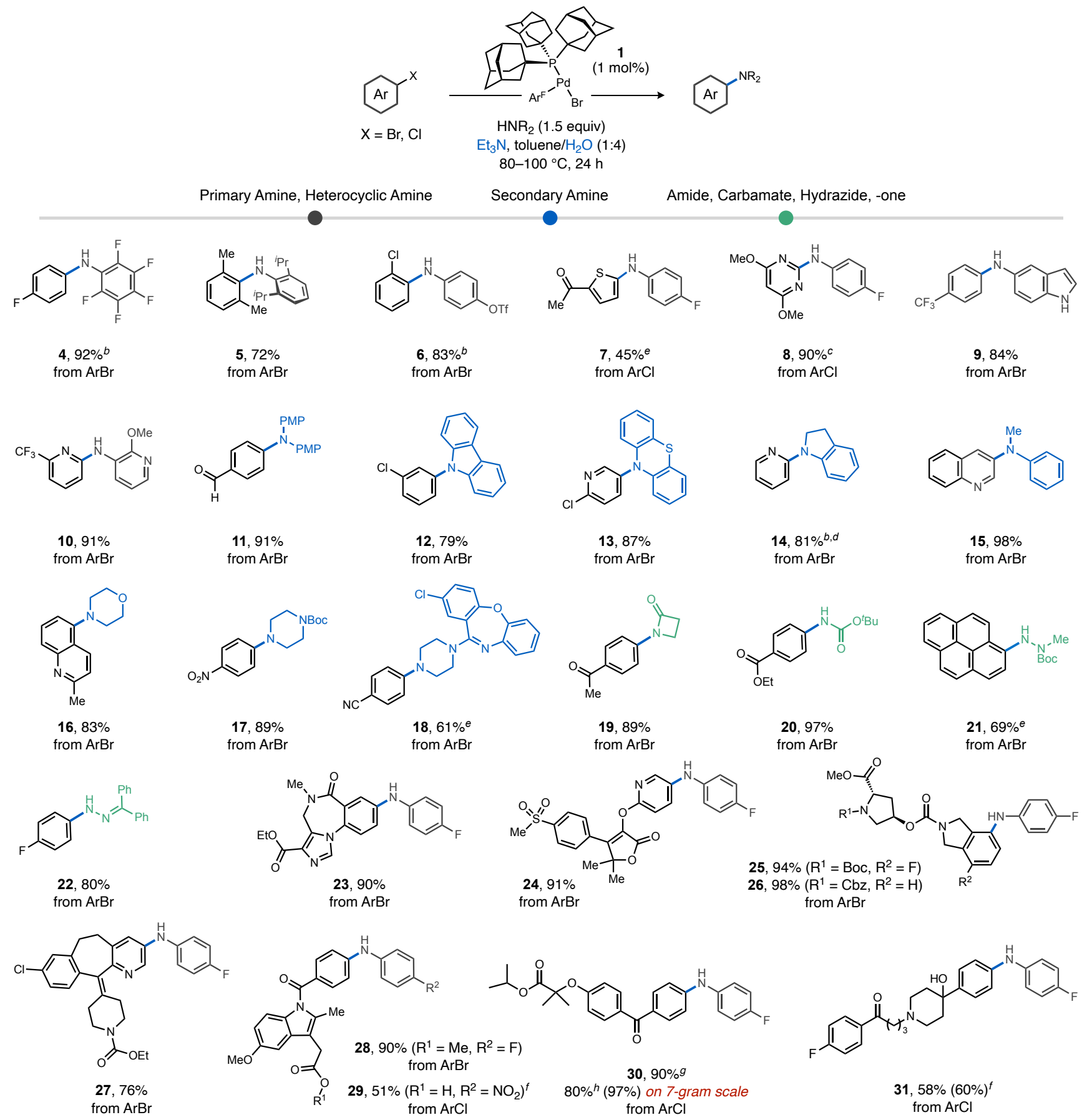

${ }^{2}$ Standard conditions: Aryl halide $(0.2 \mathrm{M})$, amine (1.5 equiv), $\mathrm{Et}_{3} \mathrm{~N}$ ( 2 equiv), and catalyst $\mathbf{1}(1 \mathrm{~mol} \%)$ were stirred in a toluene $/ \mathrm{H}_{2} \mathrm{O}(1: 4)$ mixture at $80^{\circ} \mathrm{C}(\mathrm{X}=\mathrm{Br})$ or $100^{\circ} \mathrm{C}(\mathrm{X}=\mathrm{Cl})$ in a sealed vial over $24 \mathrm{~h}$. Isolated yields shown unless noted otherwise; parentheses denote yields determined by ${ }^{19} \mathrm{~F}$ NMR vs. $\mathrm{CF}_{3} \mathrm{C}_{6} \mathrm{H}_{5}$ as internal standard or calibrated UPLC analysis. ${ }^{b}$ Neat water. ${ }^{c} 16 \mathrm{~h} .{ }^{d} 3 \mathrm{~mol} \%$ 1. ${ }^{e} 48 \mathrm{~h} .{ }^{f} 2 \mathrm{~mol} \% \mathrm{1}, 48 \mathrm{~h} .{ }^{g} 36 \mathrm{~h} .{ }^{h} t-\mathrm{AmOH} / \mathrm{H} 2 \mathrm{O}$ (1:3), $85^{\circ} \mathrm{C}$ for $12 \mathrm{~h} . \mathrm{Ar}^{\mathrm{F}}=4-\mathrm{FC}_{6} \mathrm{H}_{4} \cdot \mathrm{PMP}=4-\mathrm{MeOC}_{6} \mathrm{H}_{4}$.

alcohol as solvent. At a lower temperature $\left(80^{\circ} \mathrm{C}\right), t-\mathrm{AmOH}$ was superior giving 94\% conversion within $21 \mathrm{~h}$. Further increasing the reaction in $t$-AmOH to 20 -mmol scale gave an excellent solution yield (97\%) of $\mathbf{3 0}$ within $12 \mathrm{~h}$ at $85^{\circ} \mathrm{C}$ yielding $7.0 \mathrm{~g}(80 \%)$ of analytically pure (>99\%) product after crystallization. Kinetic profiling of the reaction (Figure S3) indicated $100 \%$ conversion was actually achieved within $45 \mathrm{~min}$ at $1 \mathrm{~mol} \%$ catalyst loading.
The effectiveness of the combination of a $\left(\mathrm{Ad}_{3} \mathrm{P}\right) \mathrm{Pd}$ catalyst and water in enabling catalytic turnover of bromo- and chloroarenes raised several mechanistic questions. For instance, it was not clear a priori if a similar or distinct catalytic mechanism might be operative compared to what has been proposed using an (AlPhos)Pd catalyst and DBU under anhydrous conditions (Scheme $1 \mathrm{~b}$ ). ${ }^{12,16} \mathrm{~A}$ switch in mechanism could potentially account for the improved reactivity toward bromo- and chloroarene electrophiles in this method versus 
aryl triflates as well as the lack of base inhibition observed previously. Experiments were thus conducted to interrogate the role(s) water plays in the catalytic mechanism, such as the initially hypothesized potential for on-cycle Pd intermediates to be generated from coordinated water.

Observation of the reaction of neutral complex $\mathbf{1}$ with water and $\mathrm{Et}_{3} \mathrm{~N}$ in toluene by ${ }^{31} \mathrm{P}$ NMRspectroscopy indicated clean formation of a new palladium complex after $1 \mathrm{~min}$ (Figure 3a). Based on comparison to an independently prepared sample, this new species was assigned as the $\mu$-hydroxo complex 32. A dimeric solution structure for 32 is suggested by the observation in the ${ }^{1} \mathrm{H}$ NMR spectrum of a single upfield resonance virtually coupled to phosphorus $\left(\delta_{\mathrm{H}}=-2.12\right.$ ppm, $\left.J\left({ }^{31} \mathrm{P}-{ }^{1} \mathrm{H}\right)=3.2 \mathrm{~Hz}\right)$ corresponding to a $\mu-\mathrm{OH}$ ligand and an anti disposition of $\mathrm{PAd}_{3}$ ligands. Importantly, the time frame for this stoichiometric reaction is far less than that required for the respective catalytic aminations in Table 1 even at a much lower temperature, which suggests formation of Pd hydroxo species from water and $\mathrm{Et}_{3} \mathrm{~N}$ is a kinetically viable step during catalysis. On the other hand, addition of water or $\mathrm{Et}_{3} \mathrm{~N}$ individually to $\mathbf{1}$ led to no detectable changes in the ${ }^{31} \mathrm{P}$ NMR spectra. Based on the above data together with the observation that substitution of water and $\mathrm{Et}_{3} \mathrm{~N}$ for phosphate buffer ( $\mathrm{pH} 8.0)$ in the catalytic reaction completely suppressed conversion, we propose 32 forms through initial equilibrium hydrolysis of $\mathbf{1}$ to generate a cationic Pd intermediate rather than by direct substitution of halide at palladium by a low concentration of free hydroxide ions.

a)

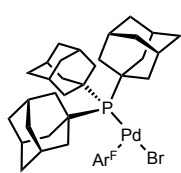

1

$1.25 \mathrm{mM}$

b)

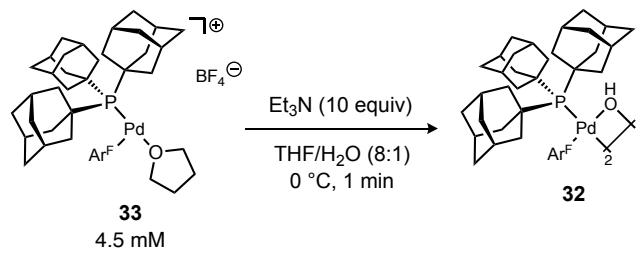

Figure 3. Stoichiometric $\mathrm{O}-\mathrm{H}$ heterolysis reactions initiated from (a) neutral or (b) cationic aryl-palladium complexes using water and $\mathrm{Et}_{3} \mathrm{~N}$. ${ }^{a} \mathrm{No}$ conversion was observed in the absence of added $\mathrm{H}_{2} \mathrm{O}$ or $\mathrm{Et}_{3} \mathrm{~N}$. $\mathrm{Ar}^{\mathrm{F}}$ $=4-\mathrm{FC}_{6} \mathrm{H}_{4}$

Deprotonation of a strongly acidified aqua ligand by $\mathrm{Et}_{3} \mathrm{~N}$ in a cationic Pd species would be expected to be facile. An analogous cationic pathway for B-to-Pd transmetalation was postulated in our previous study of weak base Suzuki-Miyaura coupling. ${ }^{20}$ To further probe if such a process could be operative in the present amination reactions, a discrete cationic species $\left[\mathrm{Pd}\left(\mathrm{PAd}_{3}\right)\left(\mathrm{Ar}^{\mathrm{F}}\right)(\mathrm{THF})\right]^{+} \mathrm{BF}_{4}^{-}$ (33) was prepared at low temperature according to a reported procedure. ${ }^{20}$ Treatment of 33 with water and $\mathrm{Et}_{3} \mathrm{~N}$ at $0{ }^{\circ} \mathrm{C}$ in THF for 1 min again led to clean formation of the Pd hydroxo complex 32 (Figure $3 \mathrm{~b}$ ). This faster reaction is consistent with a cationic aqua complex being a competent intermediate in the conversion of the palladium halide complex 1 to the palladium hydroxo complex 32, considering that exchange of the labile solvento ligand in $\mathbf{3 3}$ for water should occur readily. Furthermore, water could also play a role in driving the reaction forward by sequestering the resulting ammonium salts. Finally, the presumed basicity of the hydroxo ligand was confirmed by the immediate reversion of $\mathbf{3 2}$ back to 33 upon treatment with $\mathrm{HBF}_{4}$ etherate in $\mathrm{THF}$ at $-25^{\circ} \mathrm{C}$ (Figure $\mathrm{S} 10$ ).

While palladium hydroxo complexes have been proposed as intermediates in numerous cross-coupling reactions, their formation is generally believed to require anion exchange processes using stoichiometric ionic bases. Hydrolysis of halide ligands in a nonpolar organic solvent represents a unique and much milder pathway to access these versatile intermediates, yet such ionization processes have been proposed to be energetically prohibitive. ${ }^{9}$ This issue has been mitigated by moving away from halide electrophiles to those with weaker anions (e.g., triflate) or by addition of halide abstracting reagents (i.e., $\mathrm{Ag}^{+}, \mathrm{Tl}^{+}$), such as in methods that access the cationic pathway for the Mizoroki-Heck reaction..$^{33}$ Our data suggest that an appropriate coordinatively-unsaturated metal intermediate, such as the T-shaped $\left(\mathrm{Ad}_{3} \mathrm{P}\right) \mathrm{Pd}(\mathrm{II})$ species in this work, can in fact undergo facile ionization through hydrolysis even in toluene, which allows deprotonation of the resultant acidified aqua ligand in the cationic complex using very mild bases. To our knowledge, such a process represents a novel pathway for a key catalytic step of Buchwald-Hartwig amination reactions that activates the substrate amine, which engenders advantages in the electrophile scope to include more strongly coordinating anions (e.g., $\mathrm{Br}, \mathrm{Cl}$ ) without the need for halide scavengers.

Scheme 2. Proposed catalytic cycle for $\left(\operatorname{Ad}_{3} P\right) P d$-catalyzed, water-assisted amination.

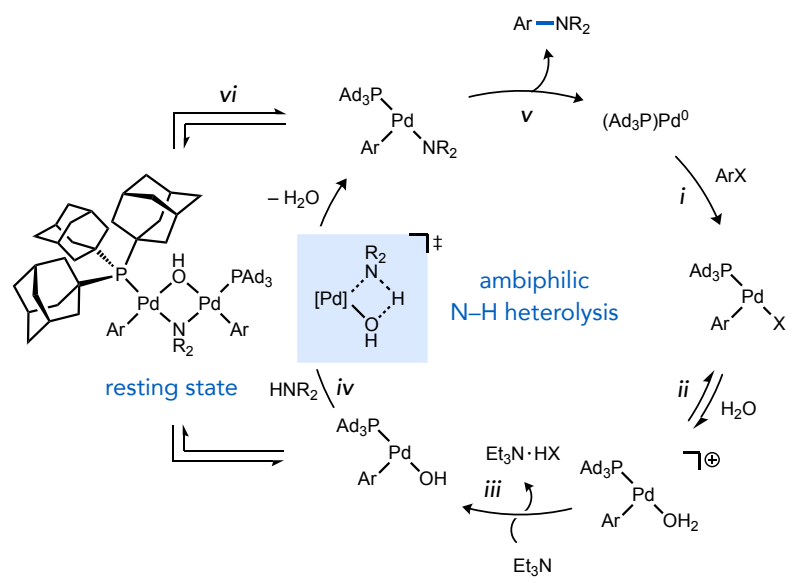

A catalytic cycle is proposed for $\left(\operatorname{Ad}_{3} \mathrm{P}\right) \mathrm{Pd}$-catalyzed aryl amination of aryl halides in Scheme 2, which incorporates a water-assisted mechanism to generate an ambiphilic Pd hydroxo species. To probe the turnover-limiting step, the experimental rate law (eq 1) was determined using either Burés' variable time normalization analysis ${ }^{34}$

$$
\frac{\mathrm{d}[\mathbf{3}]}{d \mathrm{t}}=k_{\mathrm{obs}}\left[\mathrm{Ar}^{\mathrm{F}} \mathrm{Br}\right]^{0}\left[\mathrm{H}_{2} \mathrm{NPh}\right]^{0}\left[\mathrm{Et}_{3} \mathrm{~N}\right]^{0}[\mathbf{1}]^{1}
$$

or initial rate measurements for reactions of $4-\mathrm{BrC}_{6} \mathrm{H}_{4} \mathrm{~F}\left(\mathrm{Ar}{ }^{\mathrm{F}} \mathrm{Br}\right)$ with aniline under the standard conditions of Table 1 (see Figures S31S34). The observation of a zeroth-order dependence of the initial rates on $\left[\mathrm{Ar}^{\mathrm{F}} \mathrm{Br}\right]$ and $\left[\mathrm{Et}_{3} \mathrm{~N}\right]$ suggest neither oxidative addition (step i) nor deprotonation of water (step iii) are turnover-limiting, respectively, in the catalytic reaction. These results contrast prior work on amination of aryl triflates where either a positive order dependence on [DIPEA] signified rate-determining $\mathrm{N}-\mathrm{H}$ deprotonation using a 
tertiary amine base, or a negative order dependence on [DBU] under different conditions indicated catalyst poisoning by this base. ${ }^{16}$

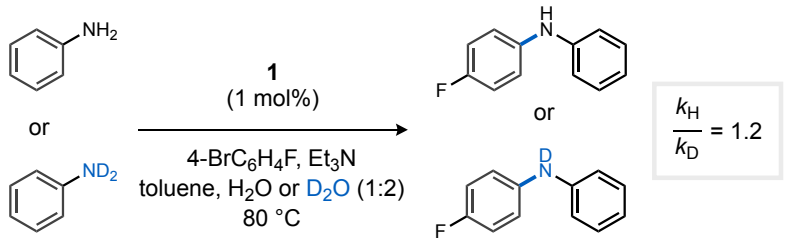

Figure 4. Determination of kinetic isotope effect from independent catalytic amination reactions of aniline or aniline- $d_{2}$.

While the zeroth-order dependence of the rate on [amine] is consistent with fast $\mathrm{N}-\mathrm{H}$ heterolysis (step iv), it could also be manifested in a scenario in which amine coordination to Pd occurred reversibly and the equilibrium saturated in the range of concentrations tested. To distinguish between these possibilities, the kinetic isotope effect (KIE) was determined for independent reactions of $\mathrm{Ar}^{\mathrm{F}} \mathrm{Br}$ with aniline in toluene $/ \mathrm{H}_{2} \mathrm{O}$ or aniline- $d_{2}$ in toluene $/ \mathrm{D}_{2} \mathrm{O}$ (Figure 4). The absence of a primary KIE in these reactions is inconsistent with turnover-limiting $\mathrm{N}-\mathrm{H}$ heterolysis regardless of potential reversibility in amine substrate coordination.

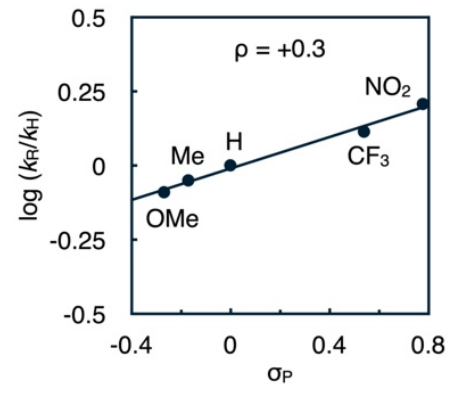

Figure 5. Hammett plot for catalytic amination of $4-\mathrm{BrC}_{6} \mathrm{H}_{4} \mathrm{~F}$ with a para-substituted aniline under the optimized conditions of Table 1 as determined by the method of initial rates.

The kinetic and isotope effect data above seem to implicate $\mathrm{C}-\mathrm{N}$ reductive elimination as the likely turnover-limiting step of catalysis. However, analysis of the initial rates for reactions using a series of para-substituted anilines (Figure 5) suggest $\mathrm{C}-\mathrm{N}$ bond formation (step $v$ ) is not rate-determining. The slope of this Hammett plot ( $\rho$ $=+0.3$ ) is inconsistent with literature data for stoichiometric reductive elimination reactions from arylpalladium amido complexes, which are generally faster for complexes with more electron-rich amido ligands $(\rho<0) .{ }^{35}$ Considering also that stoichiometric reactions (see Figure 3 ) suggest hydrolysis is kinetically facile (step ii), the available data are not consistent with any on-cycle catalytic step being turnover-limiting. An alternative kinetic scenario must then be operative during these catalytic reactions, and spectroscopic data from additional stoichiometric experiments at low temperature with isolated organometallic complexes provided several key insights in this regard.

The stoichiometric $\mathrm{N}-\mathrm{H}$ heterolysis of $\mathrm{H}_{2} \mathrm{NC}_{6} \mathrm{~F}_{5}$ by $\mathrm{Pd}$ hydroxo complex 32 in THF occurred with full conversion of 32 within $1 \mathrm{~min}$ at $-25^{\circ} \mathrm{C}$ to generate a new palladium species $\left(\delta_{\mathrm{P}} 58.8 \mathrm{ppm}\right)$ in $84 \%$ yield (Figure 6a). The stoichiometry of $\mu-\mathrm{OH}$ and $\mu-\mathrm{NHC}_{6} \mathrm{~F}_{5}$ resonances versus $\mathrm{Pd}\left(\mathrm{PAd}_{3}\right)$ and $\mathrm{Pd}\left(4-\mathrm{FC}_{6} \mathrm{H}_{4}\right)$ resonances $(1: 2$, respectively) in the ${ }^{1} \mathrm{H}$ NMR and single resonance in the ${ }^{31} \mathrm{P}$ NMR spectra suggests a syn-dinuclear complex (34), which is structurally analogous to a $\left\{\mathrm{Pd}_{2}\left(\mathrm{PPh}_{3}\right)_{2} \mathrm{Ph}_{2}(\mu-\mathrm{OH})(\mu-\mathrm{NHtBu})\right\}$ species that was crystallographically characterized by Hartwig. ${ }^{23,36}$ When $\mathbf{3 4}$ was allowed to warm to room temperature, $\mathrm{C}-\mathrm{N}$ reductive elimination occured completely to form 4 in $93 \%$ yield, relative to both $[\mathrm{Pd}]-\mathrm{Ar}^{\mathrm{F}}$ equivalents in the starting dimer complex 32, as determined by ${ }^{19} \mathrm{~F}$ NMR versus octafluorotoluene as standard. A yield of product 4 in excess of $50 \%$ necessitates the $\mu-\mathrm{OH}$ ligand in the dinuclear intermediate 34 further reacts with the remaining $\mathrm{H}_{2} \mathrm{NC}_{6} \mathrm{~F}_{5}$ in solution after $\mathrm{C}-\mathrm{N}$ bond formation is triggered. The identification of this dinuclear species (34) can also resolve the issue of the turnover-limiting step during catalysis. Specifically, the observed reaction constant of $\rho=+0.3$ is consistent with rate-determining fragmentation of the $\mu$ anilido ligand in species analogous to 34 , which should be faster with decreasing ligand $\sigma$-donicity induced by withdrawing anilido substituents. Fragmentation of this dinuclear catalyst resting state is still consistent with a first-order dependence of the rate on $[\mathbf{1}]$ because dissociation of the dinuclear species into one equivalent of $\mathrm{Pd}\left(\mathrm{PAd}_{3}\right)(\mathrm{Ar}) \mathrm{NR}_{2}$ (plus a $\mathrm{Pd}\left(\mathrm{PAd}_{3}\right)(\mathrm{Ar}) \mathrm{OH}$ fragment) generates only one equivalent of product per turnover.

a)
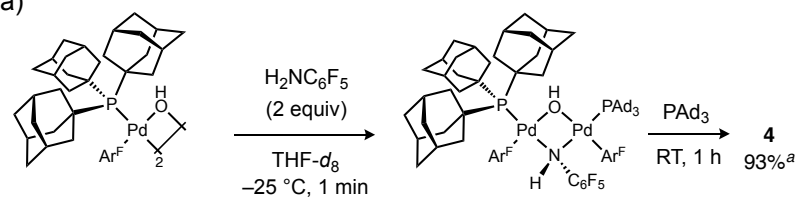

32

$$
4.2 \mathrm{mM}
$$$$
34
$$

b)

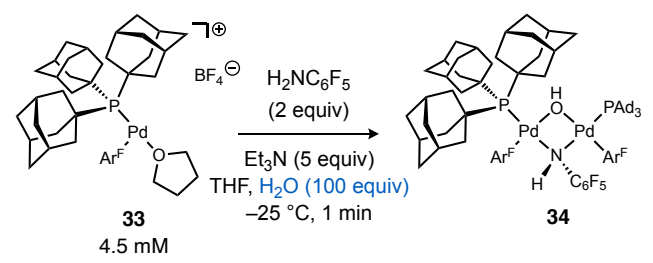

c)

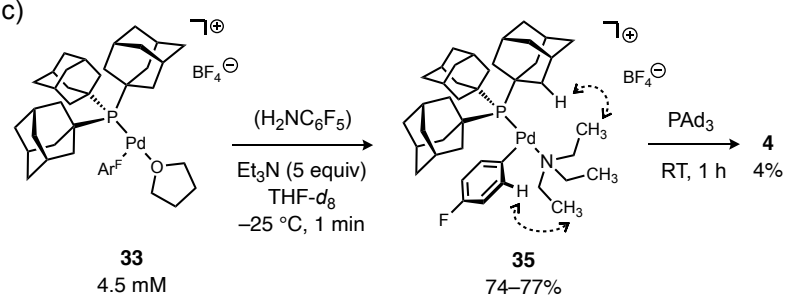

Figure 6. Stoichiometric $\mathrm{N}-\mathrm{H}$ heterolysis reactions between aryl-palladium complexes, $\mathrm{H}_{2} \mathrm{NC}_{6} \mathrm{~F}_{5}$, and $\mathrm{Et}_{3} \mathrm{~N}$ with or without added water and characterization of the resulting amido-Pd or amino-Pd intermediates. Dashed lines indicate NOE-correlated ${ }^{1} \mathrm{H}$ nuclei. ${ }^{a}$ Relative to both $[\mathrm{Pd}]-\mathrm{Ar}^{\mathrm{F}}$ equivalents in 32. $\mathrm{Ar}^{\mathrm{F}}=4-\mathrm{FC}_{6} \mathrm{H}_{4}$.

The reaction of cationic complex 33 with $\mathrm{H}_{2} \mathrm{NC}_{6} \mathrm{~F}_{5}$, excess water, and $\mathrm{Et}_{3} \mathrm{~N}$ in THF also occurred within $1 \mathrm{~min}$ at $-25^{\circ} \mathrm{C}$ to generate the same dinuclear intermediate 34 (Figure 6b). In contrast, an analogous reaction of 33 with $\mathrm{Et}_{3} \mathrm{~N}$ in the absence of added water (Figure $6 \mathrm{c}$ ) led to the consumption of starting material but generated a distinct product $\left(\delta_{\mathrm{P}} 41.5 \mathrm{ppm}\right)$ as shown in Figure 7. Characterization of this species by ${ }^{1} \mathrm{H}$ and ${ }^{1} \mathrm{H}-{ }^{1} \mathrm{H}$ NOESY NMR is consistent with a cationic, $\mathrm{Et}_{3} \mathrm{~N}$-coordinated structure (35). Importantly, repetition of the reaction with added $\mathrm{H}_{2} \mathrm{NC}_{6} \mathrm{~F}_{5}$ led to formation of the same species (Figure 7), but upon warming to room temperature only a trace (4\%) of C-N coupling product 4 formed after $1 \mathrm{~h}$. We interpret these results as suggesting that aniline substrates struggle to displace coordinated $\mathrm{Et}_{3} \mathrm{~N}$ at $\mathrm{Pd}$, and catalyst inhibition should 
occur using a soluble base as was observed previously by Buchwald. ${ }^{16}$ Because this does not appear to occur during the catalytic reactions

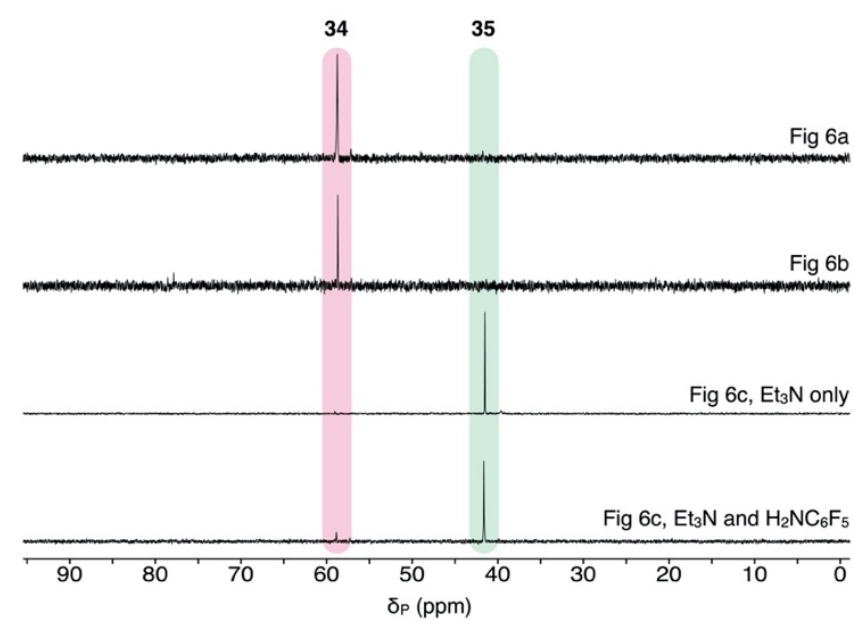

Figure $7 .{ }^{31} \mathrm{P}$ NMR spectra of stoichiometric reactions of aryl-Pd complexes 32 or 33 with amines shown in Figure 6.

of this work (reactions are zeroth- rather than inverse-order in $\left[\mathrm{Et}_{3} \mathrm{~N}\right]$ ), we postulate that another role of excess water can be to shunt catalyst away from an inactive state (e.g., 35) toward active intermediates, such as $\left[\mathrm{Pd}\left(\mathrm{PAd}_{3}\right) \operatorname{Ar}\left(\mathrm{OH}_{2}\right)\right]^{+}$and $\mathrm{Pd}\left(\mathrm{PAd}_{3}\right) \operatorname{Ar}(\mathrm{OH})$. In total, these mechanistic data strongly support a catalytic pathway unique from previous work on amination of aryl triflates using weak base for which the resting state is an off-cycle base-coordinated Pd species - an undesirable poisoned state that can be circumvented by the action of water together with the coordinative unsaturation of $\left(\mathrm{Ad}_{3} \mathrm{P}\right) \mathrm{Pd}$ catalytic species.

\section{CONCLUSION}

A method for amination of chloro- and bromo(hetero)arenes has been developed that operates efficiently with $\mathrm{Et}_{3} \mathrm{~N}$ as a mild, soluble base in combination with water in toluene. The nucleophile classes applicable to this transformation span a wide $\mathrm{p} K_{\mathrm{a}}$ range from relatively acidic amides and electron-deficient anilines to poorly acidic aliphatic secondary amines. The mild conditions are also compatible with range of base sensitive functional groups that can be problematic under classic strong base conditions, which includes carboxylic acids, esters, nitrile, nitro, and enolizable keto groups. Amination in complex settings was validated by reactions of the chloroaryl group in the pharmaceuticals indomethacin, fenofibrate, and haloperidol as well as in five drug-like bromo(hetero)arenes from the Merck informer library. Reactions can also be conducted in neat water for applications requiring single phase conditions.

Mechanistic experiments support multiple roles for water assistance in the catalytic mechanism. An initial hydrolysis of the organopalladium halide complex formed after oxidative addition is facilitated kinetically by the $\mathrm{PAd}_{3}$-enforced coordinative unsaturation of the complex, as well as thermodynamically driven through sequestration of the halide byproduct into the aqueous phase of a biphasic system. Importantly, this ionization occurs even for more strongly coordinated halide ions derived from commercially abundant bromo- and chloroarenes, which contrasts the typically difficult task of ionization $\mathrm{Pd}$ (II) complexes in nonpolar media that traditionally requires organic electrophiles with better leaving groups or halide scavengers. Deprotonation of an acidified aqua ligand in the cationic intermediate can occur readily even with $\mathrm{Et}_{3} \mathrm{~N}$, which corresponds to a considerable influence of the catalyst on relative acidities $\left(\Delta \mathrm{p} K_{\mathrm{a}}^{\text {DMSO }}=22\right)$. The ambiphilic $\mathrm{Pd}\left(\mathrm{PAd}_{3}\right)(\mathrm{Ar}) \mathrm{OH}$ intermediate that is readily accessible from water and $\mathrm{Et}_{3} \mathrm{~N}$ in these reactions features both Lewis acidic and Brønsted basic properties that, upon coordination of amine substrate, triggers an intramolecular $\mathrm{N}-\mathrm{H}$ cleavage under very mild conditions.

Stoichiometric experiments with aryl-palladium complexes implicate another unanticipated role of water in shunting catalyst speciation away from inactive, base-coordinated intermediates, which has been a challenge in other recently developed weak base amination methods. To our knowledge, this water-assisted mechanism for C$\mathrm{N}$ coupling reactions has not been previously observed and could potentially be effective in promoting other catalytic processes involving element-hydrogen bond activation under weak base conditions. The persistent coordinative unsaturation of the $\left(\mathrm{Ad}_{3} \mathrm{P}\right) \mathrm{Pd}$ catalyst thus appears to engender a number of kinetic benefits in accessing unique catalytic mechanisms for carbon-carbon and now carbon-heteroatom bond forming reactions that are attractive for catalysis in the most sensitive settings.

\section{ASSOCIATED CONTENT}

Supporting Information. This material is available free of charge via the Internet at http://pubs.acs.org.

Experimental procedures. Reaction optimization details, kinetics data, and spectral data for new compounds.

\section{Corresponding Author}

*bcarrow@princeton.edu

\section{Notes}

The authors declare the following competing financial interest(s): A patent was filed by Princeton University: Carrow, B. P.; Chen, L. WO2017/075581 A1, May 4, 2017.

\section{ACKNOWLEDGMENT}

Support was provided by the National Institutes of Health (R35GM128902). We thank Kiwoon Baeg and Lucy Wang for assistance with preliminary catalyst development and Michael Peddicord for HR-MS analyses.

\section{REFERENCES}

(1) (a) Ruiz-Castillo, P.; Buchwald, S. L.; Applications of PalladiumCatalyzed C-N Cross-Coupling Reactions. Chem. Rev. 2016, 116, 1256412649; (b) Torborg, C.; Beller, M.; Recent Applications of PalladiumCatalyzed Coupling Reactions in the Pharmaceutical, Agrochemical, and Fine Chemical Industries. Adv. Synth. Catal. 2009, 351, 3027-3043; (c) Devendar, P.; Qu, R.-Y.; Kang, W.-M.; He, B.; Yang, G.-F.; PalladiumCatalyzed Cross-Coupling Reactions: A Powerful Tool for the Synthesis of Agrochemicals. J. Agric. Food Chem. 2018, 66, 8914-8934.

(2) (a) Surry, D. S.; Buchwald, S. L.; Biaryl Phosphane Ligands in Palladium-Catalyzed Amination. Angew. Chem., Int. Ed. 2008, 47, 63386361; (b) Hartwig, J. F.; Evolution of a Fourth Generation Catalyst for the Amination and Thioetherification of Aryl Halides. Acc. Chem. Res. 2008, 41, 1534-1544; (c) Valente, C.; Çalimsiz, S.; Hoi, K. H.; Mallik, D.; Sayah, M.; Organ, M. G.; The Development of Bulky Palladium NHC Complexes for the Most-Challenging Cross-Coupling Reactions. Angew. Chem., Int. Ed. 2012, 51, 3314-3332; (d) Chartoire, A.; Nolan, S. P. CHAPTER 4 Advances in $\mathrm{C}-\mathrm{C}$ and $\mathrm{C}-\mathrm{X}$ Coupling Using Palladium-N-Heterocyclic Carbene ( $\mathrm{Pd}-\mathrm{NHC})$ Complexes. In New Trends in Cross-Coupling: Theory and Applications; The Royal Society of Chemistry: 2015, p 139-227; (e) Stradiotto, M. Ancillary Ligand Design in the Development of Palladium 
Catalysts for Challenging Selective Monoarylation Reactions. In New Trends in Cross-Coupling: Theory and Applications; Colacot, T., Ed.; The Royal Society of Chemistry: 2015, p 228-253; (f) Ingoglia, B. T.; Wagen, C. C.; Buchwald, S. L.; Biaryl monophosphine ligands in palladium-catalyzed C-N coupling: An updated User's guide. Tetrahedron 2019, 75, 4199-4211; (g) Forero-Cortés, P. A.; Haydl, A. M.; The 25th Anniversary of the Buchwald-Hartwig Amination: Development, Applications, and Outlook. Org. Process Res. Dev. 2019, 23, 1478-1483; (h) Shaughnessy, K. H.; Development of Palladium Precatalysts that Efficiently Generate LPd(0) Active Species. Isr. J. Chem. 2020, 60, 180-194.

(3) (a) Old, D. W.; Wolfe, J. P.; Buchwald, S. L.; A highly active catalyst for palladium-catalyzed cross-coupling reactions: Room-temperature Suzuki couplings and amination of unactivated aryl chlorides. J. Am. Chem. Soc. 1998, 120, 9722-9733; (b) Hartwig, J. F.; Kawatsura, M.; Hauck, S. I.; Shaughnessy, K. H.; Alcazar-Roman, L. M.; Room-Temperature PalladiumCatalyzed Amination of Aryl Bromides and Chlorides and Extended Scope of Aromatic C-N Bond Formation with a Commercial Ligand. J. Org. Chem. 1999, 64, 5575-5580; (c) Wolfe, J. P.; Buchwald, S. L.; A Highly Active Catalyst for the Room-Temperature Amination and Suzuki Coupling of Aryl Chlorides. Angew. Chem., Int. Ed. 1999, 38, 2413-2416; (d) Huang, J.; Grasa, G.; Nolan, S. P.; General and Efficient Catalytic Amination of Aryl Chlorides Using a Palladium/Bulky Nucleophilic Carbene System. Org. Lett. 1999, 1, 1307-1309; (e) Stauffer, S. R.; Lee, S.; Stambuli, J. P.; Hauck, S. I.; Hartwig, J. F.; High Turnover Number and Rapid, Room-Temperature Amination of Chloroarenes Using Saturated Carbene Ligands. Org. Lett. 2000, 2, 1423-1426; (f) Wolfe, J. P.; Tomori, H.; Sadighi, J. P.; Yin, J.; Buchwald, S. L.; Simple, Efficient Catalyst System for the PalladiumCatalyzed Amination of Aryl Chlorides, Bromides, and Triflates. J. Org. Chem. 2000, 65, 1158-1174; (g) Stambuli, J. P.; Kuwano, R.; Hartwig, J. F.; Unparalleled rates for the activation of aryl chlorides and bromides: coupling with amines and boronic acids in minutes at room temperature. Angew. Chem., Int. Ed. 2002, 41, 4746-4748; (h) Shen, Q.; Shekhar, S.; Stambuli, J. P.; Hartwig, J. F.; Highly Reactive, General, and Long-Lived Catalysts for Coupling Heteroaryl and Aryl Chlorides with Primary Nitrogen Nucleophiles. Angew. Chem., Int. Ed. 2005, 44, 1371-1375; (i) Marion, N.; Navarro, O.; Mei, J.; Stevens, E. D.; Scott, N. M.; Nolan, S. P.; Modified $(\mathrm{NHC}) \mathrm{Pd}($ allyl $) \mathrm{Cl}(\mathrm{NHC}=\mathrm{N}-$ Heterocyclic Carbene) Complexes for Room-Temperature Suzuki-Miyaura and Buchwald-Hartwig Reactions. J. Am. Chem. Soc. 2006, 128, 4101-4111; (j) Navarro, O.; Marion, N.; Mei, J.; Nolan, S. P.; Rapid room temperature Buchwald-Hartwig and SuzukiMiyaura couplings of heteroaromatic compounds employing low catalyst loadings. Chem.--Eur.J. 2006, 12, 5142-5148; (k) Biscoe, M. R.; Fors, B. P.; Buchwald, S. L.; A New Class of Easily Activated Palladium Precatalysts for Facile C-N Cross-Coupling Reactions and the Low Temperature Oxidative Addition of Aryl Chlorides. J. Am. Chem. Soc. 2008, 130, 6686-6687; (1) Shen, Q.; Hartwig, J. F.; [(CyPF-tBu)PdCl2]: An Air-Stable, OneComponent, Highly Efficient Catalyst for Amination of Heteroaryl and Aryl Halides. Org. Lett. 2008, 10, 4109-4112; (m) Fors, B. P.; Watson, D. A.; Biscoe, M. R.; Buchwald, S. L.; A Highly Active Catalyst for Pd-Catalyzed Amination Reactions: Cross-Coupling Reactions Using Aryl Mesylates and the Highly Selective Monoarylation of Primary Amines Using Aryl Chlorides. J. Am. Chem. Soc. 2008, 130, 13552-13554; (n) Organ, M. G.; Abdel-Hadi, M.; Avola, S.; Dubovyk, I.; Hadei, N.; Kantchev, E. A. B.; O'Brien, C. J.; Sayah, M.; Valente, C.; Pd-Catalyzed Aryl Amination Mediated by Well Defined, N-Heterocyclic Carbene (NHC)-Pd Precatalysts, PEPPSI. Chem. Eur. J. 2008, 14, 2443-2452; (o) Lundgren, R. J.; Sappong-Kumankumah, A.; Stradiotto, M.; A Highly Versatile Catalyst System for the Cross-Coupling of Aryl Chlorides and Amines. Chem. Eur.J. 2010, 16, 1983-1991; (p) Crawford, S. M.; Lavery, C. B.; Stradiotto, M.; BippyPhos: A Single Ligand With Unprecedented Scope in the BuchwaldHartwig Amination of (Hetero)aryl Chlorides. Chem. Eur. J. 2013, 19, 16760-16771; (q) Weber, P.; Scherpf, T.; Rodstein, I.; Lichte, D.; Scharf, L. T.; Gooßen, L. J.; Gessner, V. H.; A Highly Active Ylide-Functionalized Phosphine for Palladium-Catalyzed Aminations of Aryl Chlorides. Angew. Chem., Int. Ed. 2019, 58, 3203-3207; (r) Tappen, J.; Rodstein, I.; McGuire, K.; Großjohann, A.; Löffler, J.; Scherpf, T.; Gessner, V. H.; Palladium Complexes Based on Ylide-Functionalized Phosphines (YPhos): Broadly
Applicable High-Performance Precatalysts for the Amination of Aryl Halides at Room Temperature. Chem. Eur.J. 2020, 26, 4281-4288.

(4) Reactions using LiHMDS as base can in certain circumstances tolerate hydroxyl, amide, and carbonyl groups. See: Harris, M. C.; Huang, X.; Buchwald, S. L.; Improved Functional Group Compatibility in the Palladium-Catalyzed Synthesis of Aryl Amines. Org. Lett. 2002, 4, 28852888.

(5) Beutner, G. L.; Coombs, J. R.; Green, R. A.; Inankur, B.; Lin, D.; Qiu, J.; Roberts, F.; Simmons, E. M.; Wisniewski, S. R.; Palladium-Catalyzed Amidation and Amination of (Hetero)aryl Chlorides under Homogeneous Conditions Enabled by a Soluble DBU/NaTFA Dual-Base System. Org. Process Res. Dev. 2019, 23, 1529-1537.

(6) Shevlin, M.; Practical High-Throughput Experimentation for Chemists. ACS Med. Chem. Lett. 2017, 8, 601-607.

(7) (a) Noël, T.; Buchwald, S. L.; Cross-coupling in flow. Chem. Soc. Rev. 2011, 40, 5010-5029; (b) Schoenitz, M.; Grundemann, L.; Augustin, W.; Scholl, S.; Fouling in microstructured devices: a review. Chem. Commun. 2015, 51, 8213-8228.

(8) (a) Meyers, C.; Maes, B. U. W.; Loones, K. T. J.; Bal, G.; Lemière, G. L. F.; Dommisse, R. A.; Study of a New Rate Increasing "Base Effect" in the Palladium-Catalyzed Amination of Aryl Iodides. J. Org. Chem. 2004, 69, 6010-6017; (b) Dooleweerdt, K.; Birkedal, H.; Ruhland, T.; Skrydstrup, T.; Irregularities in the Effect of Potassium Phosphate in Ynamide Synthesis. J. Org. Chem. 2008, 73, 9447-9450.

(9) Sunesson, Y.; Limé, E.; Nilsson Lill, S. O.; Meadows, R. E.; Norrby, P.-O.; Role of the Base in Buchwald-Hartwig Amination. J. Org. Chem. 2014, 79, 11961-11969.

(10) (a) Shekhar, S.; Ryberg, P.; Hartwig, J. F.; Mathew, J. S.; Blackmond, D. G.; Strieter, E. R.; Buchwald, S. L.; Reevaluation of the Mechanism of the Amination of Aryl Halides Catalyzed by BINAP-Ligated Palladium Complexes. J. Am. Chem. Soc. 2006, 128, 3584-3591; (b) Shekhar, S.; Hartwig, J. F.; Effects of Bases and Halides on the Amination of Chloroarenes Catalyzed by $\mathrm{Pd}(\mathrm{PtBu} 3) 2$. Organometallics 2007, 26, 340351.

(11) (a) Buitrago Santanilla, A.; Christensen, M.; Campeau, L.-C.; Davies, I. W.; Dreher, S. D.; P2Et Phosphazene: A Mild, Functional Group Tolerant Base for Soluble, Room Temperature Pd-Catalyzed C-N, C-O, and C-C Cross-Coupling Reactions. Org. Lett. 2015, 17, 3370-3373; (b) Buitrago Santanilla, A.; Regalado, E. L.; Pereira, T.; Shevlin, M.; Bateman, K.; Campeau, L.-C.; Schneeweis, J.; Berritt, S.; Shi, Z.-C.; Nantermet, P.; Liu, Y.; Helmy, R.; Welch, C. J.; Vachal, P.; Davies, I. W.; Cernak, T.; Dreher, S. D.; Nanomole-scale high-throughput chemistry for the synthesis of complex molecules. Science 2015, 347, 49-53; (c) Ahneman, D. T.; Estrada, J. G.; Lin, S.; Dreher, S. D.; Doyle, A. G.; Predicting reaction performance in C-N cross-coupling using machine learning. Science 2018, 360, 186; (d) Uehling, M. R.; King, R. P.; Krska, S. W.; Cernak, T.; Buchwald, S. L.; Pharmaceutical diversification via palladium oxidative addition complexes. Science 2019, 363, 405-408; (e) Baumgartner, L. M.; Dennis, J. M.; White, N. A.; Buchwald, S. L.; Jensen, K. F.; Use of a Droplet Platform To Optimize Pd-Catalyzed C-N Coupling Reactions Promoted by Organic Bases. Org. Process Res. Dev. 2019, 23, 1594-1601.

(12) Dennis, J. M.; White, N. A.; Liu, R. Y.; Buchwald, S. L.; Breaking the Base Barrier: An Electron-Deficient Palladium Catalyst Enables the Use of a Common Soluble Base in C-N Coupling. J. Am. Chem. Soc. 2018, 140, 4721-4725.

(13) Kashani, S. K.; Jessiman, J. E.; Newman, S. G.; Exploring Homogeneous Conditions for Mild Buchwald-Hartwig Amination in Batch and Flow. Org. Process Res. Dev. 2020, ASAP. doi.org/10.1021/acs.oprd.0c00018

(14) Corcoran, E. B.; Pirnot, M. T.; Lin, S.; Dreher, S. D.; DiRocco, D. A.; Davies, I. W.; Buchwald, S. L.; MacMillan, D. W. C.; Aryl amination using ligand-free $\mathrm{Ni}(\mathrm{II})$ salts and photoredox catalysis. Science 2016, 353, 279283.

(15) Li, C.; Kawamata, Y.; Nakamura, H.; Vantourout, J. C.; Liu, Z.; Hou, Q.; Bao, D.; Starr, J. T.; Chen, J.; Yan, M.; Baran, P. S.; Electrochemically Enabled, Nickel-Catalyzed Amination. Angew. Chem., Int. Ed. 2017, 56, 13088-13093. 
(16) Dennis, J. M.; White, N. A.; Liu, R. Y.; Buchwald, S. L.; Pd-Catalyzed C-N Coupling Reactions Facilitated by Organic Bases: Mechanistic Investigation Leads to Enhanced Reactivity in the Arylation of Weakly Binding Amines. ACS Catal. 2019, 9, 3822-3830.

(17) Liu, R. Y.; Dennis, J. M.; Buchwald, S. L.; The Quest for the Ideal Base: Rational Design of a Nickel Precatalyst Enables Mild, Homogeneous C-N Cross-Coupling. J. Am. Chem. Soc. 2020, 142, 4500-4507.

(18) Murthy Bandaru, S. S.; Bhilare, S.; Chrysochos, N.; Gayakhe, V.; Trentin, I.; Schulzke, C.; Kapdi, A. R.; Pd/PTABS: Catalyst for Room Temperature Amination of Heteroarenes. Org. Lett. 2018, 20, 473-476.

(19) Chen, L.; Francis, H.; Carrow, B. P.; An "On-Cycle" Precatalyst Enables Room-Temperature Polyfluoroarylation Using Sensitive Boronic Acids. ACS Catal. 2018, 8, 2989-2994.

(20) Chen, L.; Sanchez, D. R.; Zhang, B.; Carrow, B. P.; "Cationic" Suzuki-Miyaura Coupling with Acutely Base-Sensitive Boronic Acids. J. Am. Chem. Soc. 2017, 139, 12418-12421.

(21) Lennox, A. J. J.; Lloyd-Jones, G. C.; Transmetalation in the SuzukiMiyaura Coupling: The Fork in the Trail. Angew. Chem., Int. Ed. 2013, 52, 7362-7370.

(22) (a) Thomas, A. A.; Denmark, S. E.; Pre-transmetalation intermediates in the Suzuki-Miyaura reaction revealed: The missing link. Science 2016, 352, 329-332; (b) Thomas, A. A.; Wang, H.; Zahrt, A. F.; Denmark, S. E.; Structural, Kinetic, and Computational Characterization of the Elusive Arylpalladium(II)boronate Complexes in the Suzuki-Miyaura Reaction. J. Am. Chem. Soc. 2017, 139, 3805-3821.

(23) Driver, M. S.; Hartwig, J. F.; Energetics and Mechanism of Alkylamine N-H Bond Cleavage by Palladium Hydroxides: N-H Activation by Unusual Acid-Base Chemistry. Organometallics 1997, 16, 5706-5715.

(24) (a) Kuwano, R.; Utsunomiya, M.; Hartwig, J. F.; Aqueous Hydroxide as a Base for Palladium-Catalyzed Amination of Aryl Chlorides and Bromides. J. Org. Chem. 2002, 67, 6479-6486; (b) Huang, X.; Anderson, K. W.; Zim, D.; Jiang, L.; Klapars, A.; Buchwald, S. L.; Expanding Pd-Catalyzed C-N Bond-Forming Processes: The First Amidation of Aryl Sulfonates, Aqueous Amination, and Complementarity with $\mathrm{Cu}$-Catalyzed Reactions. J. Am. Chem. Soc. 2003, 125, 6653-6655; (c) Urgaonkar, S.; Verkade, J. G.; Scope and Limitations of $\mathrm{Pd} 2(\mathrm{dba}) 3 / \mathrm{P}(\mathrm{i}-$ BuNCH2CH2)3N-Catalyzed Buchwald-Hartwig Amination Reactions of Aryl Chlorides. J. Org. Chem. 2004, 69, 9135-9142.

(25) Nelson, D. J.; Nolan, S. P.; Hydroxide complexes of the late transition metals: Organometallic chemistry and catalysis. Coord. Chem. Rev. 2017, 353, 278-294.

(26) These substrates were selected based on good HPLC resolution of starting materials and product in the high throughput assay.

(27) (a) Pompeo, M.; Farmer, J. L.; Froese, R. D. J.; Organ, M. G.; RoomTemperature Amination of Deactivated Aniline and Aryl Halide Partners with Carbonate Base Using a Pd-PEPPSI-IPentCl- o-Picoline Catalyst. Angew. Chem., Int. Ed. 2014, 53, 3223-3226; (b) Brusoe, A. T.; Hartwig, J. F.; Palladium-Catalyzed Arylation of Fluoroalkylamines. J. Am. Chem. Soc. 2015, 137, 8460-8468.

(28) Note that X4 and X8 are supplied as a mixture of diastereomers, which complicates analysis of potential epimerization of the enolizable stereocenter during the reaction.
(29) Kutchukian, P. S.; Dropinski, J. F.; Dykstra, K. D.; Li, B.; DiRocco, D. A.; Streckfuss, E. C.; Campeau, L.-C.; Cernak, T.; Vachal, P.; Davies, I. W.; Krska, S. W.; Dreher, S. D.; Chemistry informer libraries: a chemoinformatics enabled approach to evaluate and advance synthetic methods. Chem. Sci. 2016, 7, 2604-2613.

(30) (a) Dallas, A. S.; Gothelf, K. V.; Effect of Water on the PalladiumCatalyzed Amidation of Aryl Bromides. J. Org. Chem. 2005, 70, 3321-3323; (b) Xu, C.; Gong, J.-F.; Wu, Y.-J.; Amination of aryl chlorides in water catalyzed by cyclopalladated ferrocenylimine complexes with commercially available monophosphinobiaryl ligands. Tetrahedron Lett. 2007, 48, 16191623; (c) Lipshutz, B. H.; Chung, D. W.; Rich, B.; Aminations of Aryl Bromides in Water at Room Temperature. Adv. Synth. Catal. 2009, 351, 1717-1721; (d) Pithani, S.; Malmgren, M.; Aurell, C.-J.; Nikitidis, G.; Friis, S. D.; Biphasic Aqueous Reaction Conditions for Process-Friendly Palladium-Catalyzed C-N Cross-Coupling of Aryl Amines. Org. Process Res. Dev. 2019, 23, 1752-1757.

(31) (a) Shaughnessy, K. H.; Beyond TPPTS: New Approaches to the Development of Efficient Palladium-Catalyzed Aqueous-Phase CrossCoupling Reactions. Eur. J. Org. Chem. 2006, 2006, 1827-1835; (b) Shaughnessy, K. H. Cross-Coupling Reactions in Aqueous Media. In Palladium - Catalyzed Coupling Reactions; Wiley - VCH Verlag GmbH \& Co. KGaA: Weinheim, 2013, p 235-286; (c) Carril, M.; SanMartin, R.; Domínguez, E.; Palladium and copper-catalysed arylation reactions in the presence of water, with a focus on carbon-heteroatom bond formation. Chem. Soc. Rev. 2008, 37, 639-647; (d) Shaughnessy, K. H. Greener Approaches to Cross-Coupling. In New Trends in Cross-Coupling: Theory and Applications; The Royal Society of Chemistry: 2015, p 645-696.

(32) Zhang, C.; Vinogradova, E. V.; Spokoyny, A. M.; Buchwald, S. L.; Pentelute, B. L.; Arylation Chemistry for Bioconjugation. Angew. Chem., Int. Ed. 2019, 58, 4810-4839.

(33) Jutand, A. Mechanisms of the Mizoroki-Heck Reaction. In The Mizoroki-Heck Reaction; Oestreich, M., Ed.; John Wiley \& Sons, Ltd: West Sussex, 2009, p 1-50.

(34) Burés, J.; Variable Time Normalization Analysis: General Graphical Elucidation of Reaction Orders from Concentration Profiles. Angew. Chem., Int. Ed. 2016, 55, 16084-16087.

(35) (a) Hartwig, J. F.; Electronic Effects on Reductive Elimination To Form Carbon-Carbon and Carbon-Heteroatom Bonds from Palladium(II) Complexes. Inorg. Chem. 2007, 46, 1936-1947; (b) Arrechea, P. L.; Buchwald, S. L.; Biaryl Phosphine Based Pd(II) Amido Complexes: The Effect of Ligand Structure on Reductive Elimination. J. Am. Chem. Soc. 2016, 138, 12486-12493; (c) Peacock, D. M.; Jiang, Q.; Hanley, P. S.; Cundari, T. R.; Hartwig, J. F.; Reductive Elimination from PhosphineLigated Alkylpalladium(II) Amido Complexes To Form sp3 CarbonNitrogen Bonds. J. Am. Chem. Soc. 2018, 140, 4893-4904.

(36) Driver, M. S.; Hartwig, J. F.; Carbon-Nitrogen-Bond-Forming Reductive Elimination of Arylamines from Palladium(II) Phosphine Complexes. J. Am. Chem. Soc. 1997, 119, 8232-8245. 
Authors are required to submit a graphic entry for the Table of Contents (TOC) that, in conjunction with the manuscript title, should give the reader a representative idea of one of the following: A key structure, reaction, equation, concept, or theorem, etc., that is discussed in the manuscript. Consult the journal's Instructions for Authors for TOC graphic specifications.

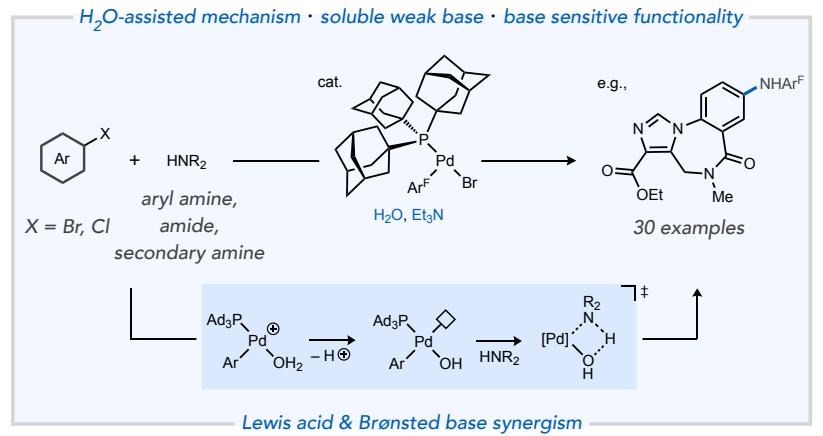

